\title{
A IMPORTÂNCIA DAS MANCHAS DE SANGUE EM LOCAL DE CRIME: ASPECTOS PERICIAIS
}

\author{
Lucilene Quintiliano Alves ${ }^{1}$ \\ Rosana Carneiro Boaventura ${ }^{2}$
}

RESUMO: A sociedade civil desde tempos pretéritos apresenta conflitos, dentro de um ponto de vista sociológico o crime representa um fenômeno normal e funcional, não obstante quando a taxa de delinquência eleva-se demostra desarranjo na ordem normativa difundindo desorganizações sociais, neste âmbito o Poder Judiciário colabora no combate à criminalidade buscando soluções judiciais para os delitos mais praticados, o estabelecimento da perícia criminal ganha respaldo legal e se consolida como um método de investigação de provas nos ambientes criminais, nesta esteira os vestígios hemáticos, são amostras mais frequentemente analisadas, tendo em vista que o sangue é um tecido vivo constituído de uma estrutura celular capaz de conduzir a identificação individual, no contexto forense tal característica é devidamente explorada, dada a relevância das manchas de sangue no local do crime, neste parâmetro este presente trabalho dedica-se a discorrer sobre os principais aspectos destas, a metodologia adotada consiste na consulta a duas teses de mestrado, onde as autoras trazem à baila as questões mais essenciais do tema.

Palavras-chaves: Medicina Legal. Manchas de Sangue. Pericia criminal.

ABSTRACT: Civil society has had conflicts since past times, within a sociological point of view crime represents a normal and functional phenomenon, despite the fact that the crime rate rises from a breakdown in the normative order spreading social disorganizations, in this context the Judiciary collaborates in the fight against criminality seeking judicial solutions to the most common crimes, the establishment of criminal expertise gains legal support, and is consolidated as a method of investigating evidence in criminal environments, in this wake the hematic traces, are samples most frequently analyzed, taking into account since blood is a living tissue made up of a cellular structure capable ofconducting individual identification, in the forensic context this characteristic is properly explored, given the relevance of blood stains at the crime scene in this parameter this present work is dedicated to discuss in the main aspects, the adopted methodology cons I was in consultation with two master's theses, where the authors bring up the main aspects of the theme.

Keywords: Forensic Medicine. Bloodstains. Criminal Expertise.

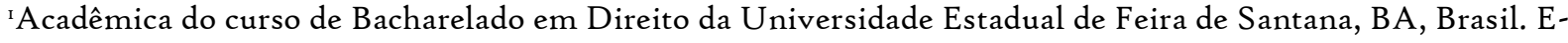
mail: cyleneroo@hotmail.com.

${ }^{2}$ Acadêmica do curso de Bacharelado em Direito da Universidade Estadual de Feira de Santana, BA, Brasil. E-mail: rosa-boaventura@hotmail.com.
} 


\section{INTRODUÇÃO}

A Medicina Legal constitui-se um ramo complexo e multidisciplinar conciliando conhecimentos nos âmbitos da Medicina e do Direito, Ambroise Paré (I510-1590) cirurgião francês que estabeleceu novas práticas no campo da medicina e deixou um vasto legado neste campo, considerado o Pai da Medicina Legal, conceitua a mesma como a aplicação dos conhecimentos médicos aos problemas jurídicos (CROCE e CROCE JÚNIOR, 2004, p.7). Por sua vez, Freire (2009, p.3) coloca que esse ramo atua na prática de atos médicos com a intenção de elaborar documentos que se consubstanciem em provas, de forma a direcionar um magistrado na resolução de distintos processos judiciais. Diante dessa exposição é aferida a relevância da Medicina Legal, visto que esta área promove trabalhos assistencialistas a prática da justiça, em busca disso a mesma envolve distintos ramos, dentre estes pode-se trazer à baila a Biologia Forense, a qual aplica seus conhecimentos na busca de vestígios biológicos com a finalidade de promover resoluções de delitos, sendo esta esfera vasta é dividida em subáreas, como a Hematologia Forense, essa dedica-se aos estudos das manchas de sangue na cena do crime, promovendo informações primordiais para as investigações periciais criminais.

Ademais, em um contexto sociológico desenvolvido por Émile Durkheim, o crime é concebido como um fato social normal, segundo o autor mencionado, este é resultado da convivência coletiva e somente será considerado pelo sociólogo como uma patologia, quando ocorre o aumento da taxa de criminalidade, nas outras situações um delito para Durkheim,

serve para consolidar o sentimento comunitário por conseguinte estabiliza a conformidade das normas e traz evolução a moral lógica-jurídica. (DURKHEIM, I895, p. 73)

Segundo a Lei de Introdução ao Código Penal Brasileiro considera-se crime a infração penal a que a Lei comina pena de reclusão ou de detenção, por meio de uma conceituação analítica do mesmo, este ocorre quando um indivíduo pratica um fato antijurídico de forma voluntária e consciente instituído como punível pela legislação. De acordo com o princípio estabelecido pelo cientista forense Edmond Locard a ocorrência do crime traz à tona a existência de três elementos, a saber, a vítima, o criminoso e o local em 
que sucede os acontecimentos, o mesmo propõe ainda que cada contato deixa um rastro, isto é o lugar que acontece o delito contém distintos vestígios e por isso deve ser realizadas investigações. (BEVEL e GARDNER, 2002, apud MONTEIRO, 2010, p.4)

Mediante a este contexto o local do crime define-se como o lugar em que ocorreu a ação delituosa, segundo o artigo 60 do Código Penal Brasileiro, nesta localização é possível encontrar as características que configura a transgressão penal, por isso quando a força policial toma ciência de um delito ao chegar no espaço do acontecimento, o primeiro passo é restabelecer a ordem pública e posteriormente promover a preservação do ambiente através do isolamento, a vista de evitar quaisquer formas de contaminações que provoque a eliminação de provas, após superar essa fase deve ser acionada a equipe de peritos criminais para investigação dos elementos constituintes do crime. Cabe aos peritos, saber lidar com a cena do ato criminoso, e localizar os vestígios com maior probabilidade de produzir respostas satisfatórias a pesquisa, os mesmos necessitam estar devidamente equipados, para efetuar a recolha, deposito no recipiente adequado, como também realizar a condução dos vestígios ao laboratório criminal.

Ocorrem distintas classificações a respeito das categorias dos vestígios proporcionada pelos autores, em termos simplórios pode-se distinguir três tipos de vestígios, quais sejam, vestígios inorgânicos, são aqueles integrados por compostos não biológicos, como explosivos, tinta, vestígios morfológicos, são os que estão relacionados aos traços humanos externos, como a impressão digital, e por fim vestígios biológicos, que são compostos por excrementos, secreções ou fluido de origem humana, a exemplo do sangue disposto através de manchas, esse é um vestígio facilmente encontrados na cena do crime, tornando-se de extrema importância por causa de seu potencial identificador, dado que este carrega em si mesmo grandes fontes do material genético, além disso, o mesmo através dos seus grupos como o sistema $\mathrm{ABO}$ ou $\mathrm{Rh}$ permite a individualização do sangue. (MONTEIRO, 2010, p.44)

Portanto este é um fluido que tem uma alta aptidão probatória, pois no cenário judicial, este permite não somente identificar agressor ou vítima, mas também propicia indicar, qual foi o tipo de arma utilizada na infração, número de golpes ou estabelecer o tempo dos ferimentos, isso se torna possível mediante a análise dos padrões de manchas de 
sangue localizados pelos peritos na cena do crime. Diante da notoriedade do sangue no âmbito forense, optou-se neste trabalho, pormenorizar os distintos formatos das manchas de sangue e os dados periciais que estes fornecem.

\section{IMPORTÂNCIA DO SANGUE NA MEDICINA LEGAL}

O sangue em contexto amplo pode ser analisado como um liquido corporal, produzido no tecido hemocitopoético, desempenhando funções vitais no organismo. No quadro forense o mesmo realiza um papel essencial, dado que este é um fluido complexo, que traz em si mesmo informações capazes de conduzir à identificação de indivíduos considerados suspeitos ligados a prática de determinado crime, ou até mesmo na identificação do ofendido. Além disso, o mesmo é um dos vestígios biológicos comumente encontrados nas ocorrências criminais, a análise deste auxilia na reconstrução das ações praticadas tanto pela vítima como pelo agressor. Ademais, os vestígios de manchas de sangue em cenas de crimes violentos, como homicídios, acabam por colaborar para resolução do mesmo (MONTEIRO, 2010, p.58). Cabe aqui pontuar em pormenores posteriormente, as funções deste e seus aspectos principais desempenhando no corpo humano e como estes influenciam na caracterização das manchas de sangue.

Além disto, no século XX, Karl Landsteiner observou que quando eram misturados sangues de distintas pessoas sucedia a aglutinação das hemácias, concluindo que existia incompatibilidade sanguínea, com isso foi inferido que existia alguns tipos de sanguíneos, sendo conceituado de $\mathrm{A}, \mathrm{B}, \mathrm{AB}, \mathrm{O}$, derivando o sistema $\mathrm{ABO}$, estes são determinados pela presença ou ausência de aglutinogênios e aglutinas em suas hemácias. E ainda existe outro sistema de grupos que cabe ser citado aqui, a saber, o fator $\mathrm{Rh}$, descoberto por meio do sangue do macaco Rhesus, a partir desse é possível identificar se este é positivo ou negativo, pois alguns tipos possuem a presença do fator $R h$, com isso existem $R h$ positivos $(R h+)$ e as hemácias que se aglutinam são chamadas de $\mathrm{Rh}$ negativos ( $\mathrm{Rh}-$ ). Esses sistemas de grupos no contexto forense permitem a exclusão de suspeitos, dessa forma as investigações podem avançar para outras ponderações evitando vereditos equivocados. (MONTEIRO,2010, p.69)

Vale citar que a Genética Forense apresentou grandes avanços, hodiernamente é também utilizado o ADN (ácido desoxirribonucleico) moléculas biológicas contendo todas 
as informações genéticas que forma as características individuais, o que contribui no meio pericial na identificação dos suspeitos, bem como no reconhecimento de erros relacionados a condenação de indivíduos inocentes. (MONTEIRO,20Io, p.6o-6I)

\title{
2.I PRINCIPAIS ASPECTOS SANGUÍNEO
}

O sistema cardiovascular humano além de ser composto pelo coração possui atuação também dos vasos sanguíneos, sendo caracterizado como um sistema de tubos por meio do qual ocorre a circulação do sangue. Esse exerce funções primordiais no corpo humano agindo tanto como transporte de substâncias e gases respiratórios como na defesa do organismo, auxilia também na regulação da temperatura humana, e no processo de coagulação. Ademais, Monteiro em sua pesquisa apontou o funcionamento do sangue no corpo humano e como este contribui para a manutenção da vida:

\begin{abstract}
A circulação sistémica do sangue inicia-se com o bombeamento do mesmo, pelo coração, através das artérias até aos capilares, designado de sangue arterial. Nos capilares, ocorrem as trocas entre o sangue e as células, ou seja, do sangue saem o oxigénio e os nutrientes e, em troca, recebe o dióxido de carbono e os resíduos das células. Posteriormente, o sangue abandona os capilares, designado sangue venoso e, através das veias, retorna ao coração. De forma a elevar o nível de oxigenação do sangue, inicia-se a circulação pulmonar, onde o sangue é bombeado até aos pulmões e volta ao coração, para iniciar um novo ciclo. (MONTEIRO, 2013, p.6r)
\end{abstract}

No que concerne as propriedades físicas do sangue concede-se destaque a sua viscosidade, tensão superficial e densidade relativa, conhecer tais propriedades é fundamental para compreender os meios que conduziram o aparecimento dos padrões de manchas de sangue e a aparência destas. (NOGUEIRA, 2013, p. 36)

A viscosidade refere-se à resistência de um liquido a mudança de fluxo quando sujeito a uma tensão, dessa forma quando este é mais viscoso dificilmente terá escoamento, no caso especifico do sangue, esse é um fluido não newtoniano, ou seja, sua viscosidade não é constante e tem a mesma modificada com a elevação da temperatura. Por sua vez, a tensão superficial é exercida quando ocorre a ligação entre moléculas igualitárias localizadas na superfície do liquido, provocando um determinado crescimento das ações coesivas que leva ao mesmo suportar a atos de penetração. Por fim, a densidade relativa refere-se a razão entre a densidade de alguma substância e a densidade da água, no caso deste liquido possui densidade de $1.06 \mathrm{~g} / \mathrm{cm}$, aplicando a Segunda Lei de Newton, a qual pregoa que a força 
resultante que atua sobre um corpo é igual ao produto de sua massa pela aceleração, percebese que na situação do sangue a potência aplicada sobre o mesmo será o fator primordial para o estabelecimento dos padrões de manchas de sangue por esta gerada. Com isso, estas propriedades associadas as forças exercidas provocam os diâmetros da mancha de sangue. (NOGUEIRA, 2013, P.36-37)

\subsection{COMPOSIÇÃO DO SANGUE}

Em relação a sua composição o sangue é integrado por diversas estruturas, como o plasma, liquido amarelado, composto por água e proteína, responsável pelo transporte de substâncias, e é composto também pelas seguintes células, eritrócitos, leucócitos e plaquetas formadas por hematopoiese na medula óssea. Os eritrócitos podem ser caracterizados como células anucleadas, em formato bicôncavo, em tom avermelhado, esta célula é produzida em grandes quantidades no organismo humano, a sua principal função é o transporte de gases respiratórios, este direciona oxigênio e nutrientes para células, e também participa da condução do dióxido de carbono para os pulmões o qual é eliminado na respiração, o mesmo é composto por uma proteína denominada de hemoglobina, repleta de ferro, considerada também como pigmento respiratório, responsável pela cor vermelha do sangue, a mesma ainda é formada por uma porção proteica (globina) e um grupo prostético (heme), no contexto forense a identificação da mancha suspeita é o primeiro passo a ser seguido, quando este liquido é expelido do corpo por meio de uma lesão, a hemoglobina sofre um processo de oxidação, com isso o sangue presente nas manchas contém atividades catalíticas, as quais serão utilizadas nos testes presuntivos e de certeza da identificação desse fluido. (NOGUEIRA, 2013, p.34)

Ao seu modo os leucócitos também chamados de glóbulos brancos, são células incolores, e que possui núcleo, estes são importantes componentes do sistema imunológico, trabalhando para a defesa do organismo humano por meio de três modos, fagocitose onde ocorre a captura, englobamento e destruição das células consideradas entranhas, a defesa passiva caracterizada pela produção de anticorpos e por último o processo de diapedese, aqui ocorre a passagem dos leucócitos através da parede dos vasos, impedindo assim infecções. A relevância dos leucócitos na Medicina Legal, refere-se à possibilidade de extração de DNA, 
localizado nestas células presentes em uma mancha de sangue. Após a coleta do material genético, ocorre o cruzamento dessas informações por meio do Banco de dados de Perfis Genéticos, permitindo assim a identificação do suspeito, conforme o artigo $9^{\circ} \mathrm{A}$ da Lei de Execução Penal, Lei no 7.210 de II de julho de 1984. (Op cit, 2013, p.35)

As plaquetas são produzidas na medula óssea e atuam na área de coagulação do sangue, com formato discoide a irregular e estrutura complexa, quando ocorre um ferimentos estas entram em ação, onde as mesmas tapam as paredes dos vasos expostos com isso impedindo uma hemorragia, na cena de um crime a coagulação é um importante fator de observação, pois através da mesma se torna possível estimar o tempo decorrido após da morte da vítima (Op cit, 2013, p.36). Posteriormente ao exame dos principais componentes do sangue, e como estes influenciam positivamente no âmbito forense, cabe agora, prosseguir o estudo analisando os padrões de manchas de sangue.

\section{ANÁliSE DE PADRÕES DE MANCHAS DE SANGUE}

A partir de uma perspectiva histórica verifica-se que a utilização da análise dos padrões de manchas de sangue como técnica investigativa é uma prática recente, despontando em meados do século XIX. O primeiro trabalho expressivo desenvolvido a cerca desse assunto foi dirigido por Eduard Piotrowski, membro do Instituto de Medicina Forense localizado na Polônia, nos seus estudos o mesmo apontou "a relação entre a cauda da mancha de sangue e a direção em que a gota voava aquando do impacto”3. Desde então diversos trabalhos foram formados ao longo do tempo, recebe destaque também os estudos de Herbert Leon MacDonell, apontado como o pai da análise de padrões de manchas de sangue dos tempos modernos ${ }^{4}$.

Esse recebe o título mencionado devido às robustas contribuições para essa área, cabe aqui citar alguns dos seus feitos, MacDonell é autor de duas obras publicadas com grande aclamação dos especialistas internacionais, a saber, "Flight Characteristics and Stain Patterns of Human Blood," onde é exposto pontos em relação a duplicação de padrões e

\footnotetext{
${ }^{3}$ BEVEL \& GARDNER, 2008 apud NOGUEIRA, 2013, p..43.

${ }^{4}$ JAMES \& KISH, 2005; BEVEL \& GARDNER, 2008 apud NOGUEIRA, 2013, p.44
} 
manchas de sangue examinados no contexto criminal, e "Bloodstain Pattern Interpretation" neste é trazido os aspectos principais sobre os padrões de manchas de sangue correlacionando a melhor maneira de aplicar esse conhecimento na investigação criminal. O mesmo ainda foi pioneiro ao estabelecer o primeiro programa básico de treino para a interpretação de padrões de manchas de sangue e o primeiro Instituto de Manchas de Sangue no Mississipi criado em 1973, e após uma década é formado pelo próprio a International Association of Bloodstain Pattern Analysts, onde são integrados componentes de várias partes do mundo, tendo como objetivos padronizar as técnicas científicas de Análise de Padrão de Mancha de Sangue, bem como promover a educação e incentivar a pesquisa nessa área especifica5.

Ademais, no contexto brasileiro recebe destaque nessa área o perito criminal Antonio Augusto Canelas Neto, considerado especialista internacional de perícias em perfis manchas de sangue, membro da Internacional Association of Bloodstain Pattern Analysts-IABPA, citada anteriormente, sendo autor do livro "Perfis de Manchas de Sangue: do local de crime à elaboração do laudo" na obra é tratado em suma desde as propriedades especificas do sangue até a classificação das manchas de sangue e sua aplicação nos laudos periciais. (CANELAS NETO, 2017)

Em linhas gerais, a análise de padrões de manchas de sangue, dedica-se ao estabelecimento da relação entre as formas das manchas de sangue e quais fatores externos e internos ocasionaram a sua posição. $\mathrm{O}$ investigador que procede esta pesquisa deve captar primeiramente os distintos padrões das manchas de sangue, modelos estes definidos pela origem de arremesso da gota, posteriormente o mesmo procederá o exame individual destes, pois cada detalhe se torna essencial na busca de solucionar quesitos como, que tipo de arma foi usada pelo agressor, as quantidades de golpes deferidos, a origem do sangue, a sua velocidade e o seu ângulo de impacto, as posições antes durante e depois do delito da vítima e do agressor, cronologia dos ferimentos, enfim procura-se a reconstrução da cena do crime. (NOGUEIRA, 2013, p. 42)

\footnotetext{
${ }^{5}$ Op cit, p.44-45.
} 
Para auxiliar nesta investigação o perito criminal recorre a técnicas de identificação e recolha no local do crime, o mesmo pode utilizar exame macroscópico, testes de presunção e teste de espécie. Na primeira categoria encontra-se como principal mecanismo o sistema de luz de varrimento, para localização inicial de manchas de sangue e seus percursos. Os testes de presunção é utilizado na constatação inicial dos vestígios de sangue, sendo usado métodos quimiolumenescente, destacando-se o luminol (quando oxidado com o peróxido de hidrogênio emite uma luz azulada que permite resgatar os resíduos que foram ofuscados a partir da tentativa de limpeza ou eliminação da mancha de sangue), Kastel-Meyer (a mancha de sangue é colhida e tratada com pequenas quantidades de etanol para possibilitar o aumento de sensibilidade do teste, ainda é adicionado fenolftaleína, se a substância mudar de cor tem resultado negativo não se tratando de uma mancha de sangue), reagente de benzidina (este teste possui maior sensibilidade e qualidade, a benzidina é misturada ao peróxido de hidrogênio, caso a amostra contenha sangue, o oxigênio presente neste vai oxidar e este reagente libera uma coloração azulada). (MONTEIRO, 20Io, p.67-70)

Após a detecção deste é necessário ainda verificar se trata de sangue humano por meio da utilização de métodos, como o hexagon, neste ocorre a apuração mediante a reação oxidante da hemoglobina diante das quantidades de reagentes empregados, caso o teste tenha resultado positivo será formado uma linha azul (MONTEIRO, 2010, p.7I). A partir do momento que ocorre a devida identificação da mancha de sangue a mesma será recolhida por meio de materiais como tubos de colheita de sangue, papel filtro, água destilada, embalagens de plásticos para transporte de objetos, algodão e gaze esterilizada, bisturis e lâminas, pinças e tesouras, entre outros, visando com isso a forma mais segura de recolha, evitando a contaminação da amostra mediante contato com o perito, o transporte das amostras até o laboratório criminal se dará respeitando as proteções cabíveis. (NOGUEIRA, 2013, p.32) 


\section{SISTEMA DE CLASSIFICAÇÃO}

Cabe aqui estabelecer a diferenciação entre manchas de sangue e padrão de mancha de sangue, a primeira refere-se a uma certa quantidade de sangue que é disposta em uma determinado local, por sua vez, um padrão é constituído na medida que tais manchas são distribuídas numa superfície, ou seja, relaciona-se com o formato que elas assumem, de forma a indicar através de suas particularidades indícios que colaborem com a resolução do delito (NOGUEIRA, 2013, p.5o). Essa área de pesquisa devido a sua importância, possui conceitos basilares já consolidados, estes servem como fundamento para ser tomadas as devidas interpretações do fato pelos profissionais desse setor. A partir deste momento serão expostos no presente trabalho as definições mais recorrentes neste campo, subsequentemente serão elencadas as classificações referente aos padrões de manchas de sangue.

Neste meio um termo relevante é o ângulo de impacto, a forma que a mancha de sangue assume depende principalmente do ângulo agudo, ou seja, a relação entre o plano da superfície na qual ocorre o choque da gota e a direção da mesma. Os salpicos sucede quando alguma força entra em choque onde está localizado o sangue depositado, se os agregados menores do mesmo tomarem direção exterior a fonte de origem, é chamado de salpicos para frente, sendo característico a presença de manchas maiores, por outro lado se os salpicos tomar a posição de direção a fonte é denominado de salpicos para trás, possuindo uma quantidade menor de manchas, esse tipo de padrão é relevante no caso de delitos cometidos com o uso de armas de fogo, pois estes indicam a possível posição que as mãos ocupavam ao praticar o disparo. As manchas de sangue podem ser regulares, isto é são aquelas que possuem um formato bem definido podendo ser circular ou elíptica, a exemplo do jatos ou jarros arteriais, ainda existem manchas irregulares, essas não tem formato especifico. A partir do momento que a mancha de sangue tem formato elas possuem margens, que podem ser, coroa, cauda e espinho. (MONTEIRO, 2010, p.98-Ioo) 
Figura I: Tipos de borda em mancha de sangue
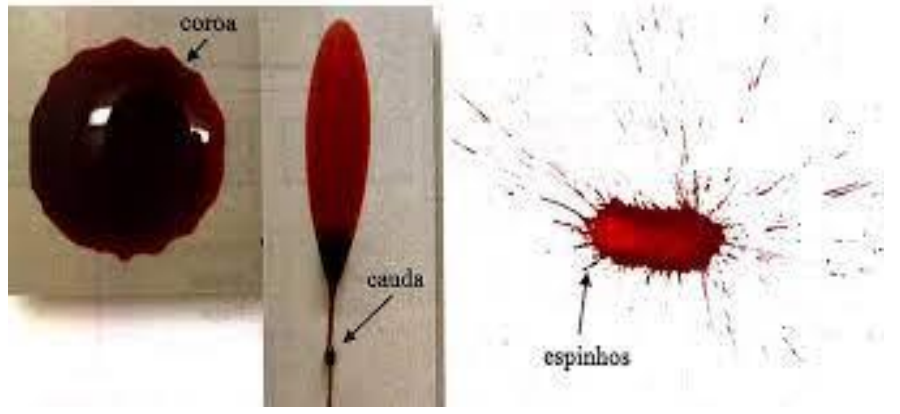

Fonte: GUAZZELLI, 2018

O coagulo é constatado quando o sangue é expelido do corpo e ocorre a separação entre as substâncias sólidas e liquidas deste, a sua avaliação aponta o tempo ocorrido entre o derrame do sangue e a formação da mancha. A direcionalidade de uma mancha é verificada a partir da direção que esse fluido se posiciona no momento que ocorreu no choque contra a superfície. As manchas primárias ou principal, são aquelas formadas a partir da colisão da gota de sangue com a superfície, destas se deriva as manchas satélites, estas se depositam em torno daquelas, que tem geralmente o tamanho maior. O ponto de impacto se configura onde uma força é exercida contra uma fonte de sangue, e ponto de origem é o local onde a gota tem sua início verificado. (MONTEIRO, 2013, p.10o-Io4)

Figura 2: Mancha de sangue principal, mancha de sangue satélite, mancha de sangue irregular
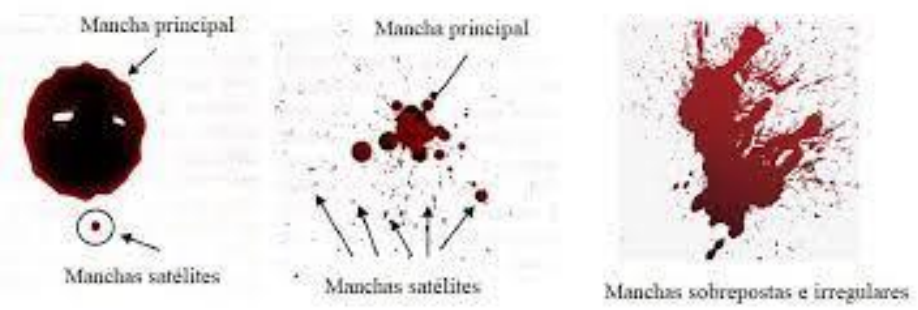

Fonte: GUAZZELLI, 2018

Após a essa breve revisão da terminologia aplicada nesta área, uniformizando a mesma, cabe prosseguir com a estruturação da classificação dos padrões das manchas de sangue, aqui será adotada a classificação sugerida por Jozef Radziki, o mesmo propõe que os padrões de manchas de sangue devem ser separados e agrupadas em quatro categorias, a 
saber, padrões de manchas de sangue passivas, que são aquelas formadas devido a posição do corpo e a atuação da gravidade estas apontam o movimento do corpo no momento do crime, padrões de manchas de sangue de impacto ocorrem devido ao choque do sangue com alguma força gerando manchas como salpicos e borrifos, padrões de mancha de sangue de transferência surge quando o sangue úmido é depositado em uma superfície e entra em contato com uma plano secundário, esse contato gera a perda total ou parcial desse fluido naquele local presente, como ocorre na tentativa de limpeza ou contato entre objetos, por fim se uma mancha não for classificadas em nenhuma das categorias anteriormente citadas é atribuída a categoria denominada heterogéneo\miscelânea. (MONTEIRO, 2013, p.ı6)

\section{I PADRÃO PASSIVO}

No padrão passivo é enquadrado quatro padrões de manchas de sangue, sendo estes jatos ou jarros arteriais, padrão de gotejamento, padrão de saturação e poças de sangue. Os jatos ou jarros arteriais são caracterizados da seguinte forma, as artérias transportam o sangue sob altas pressões, quando ocorre uma lesão sobre a mesma ocorre o sangramento em forma de jato constituindo um padrão zig zag. Por sua vez o padrão de gotejamento é formado quando ocorre um gotejamento de sangue em uma poça já formada, é preciso colocar que a gota de sangue assume um formato dependendo do ângulo, por exemplo se o ângulo for de $90^{\circ}$ terá um formato elíptico. No padrão de saturação tem manchas irregulares derivadas do contato entre tecidos e sangue em grandes quantidades. As poças de sangue ocorrem quando existe acúmulo deste fluído em determinada superfície (MONTEIRO, 2013, p.107-108). Na figura abaixo se verifica as manchas de sangue jatos ou jarros arteriais e padrão de gotejamento respectivamente.

Figura 3: Manchas de sangue jatos ou jarros arteriais, padrão de gotejamento.

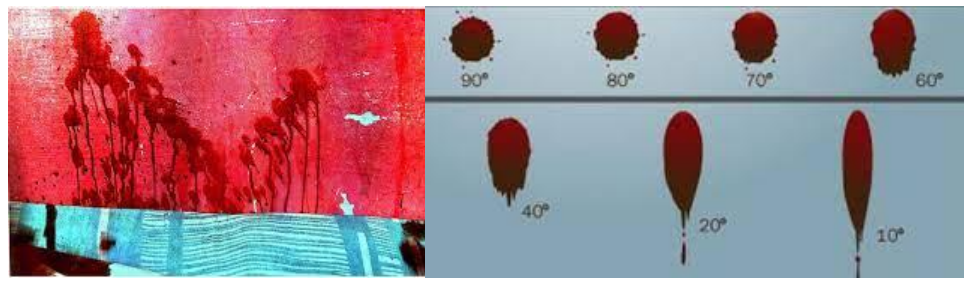

Fonte: GUAZZELLI, 2018. 


\subsection{PADRÃO DE TRANSFERÊNCIA}

Os padrões de transferência, como já citado anteriormente, são formados a partir do contato do sangue presente em dada superfície com outro espaço ou o contato com alguma pessoa que possa estar presente no momento do crime, neste movimento dentro da cena do delito o sangue pode entrar em contato com as roupas destes indivíduos, formando manchas em forma de salpicos, tendo que o perito deve diferenciar entre salpicos originados por atos violentos ou por contato, estas manchas ganham realce no âmbito de pesquisa quando o objeto que teve contato com o sangue deixa impressos digitais. Operando nesta modalidade o padrão "Swipe" onde a transferência de sangue se dar de uma fonte encontrada em movimento para um ambiente fixo, neste caso pode ser citado, como exemplo, o próprio corpo da vítima em contato com uma superfície, existe também nesta categoria o padrão "Wipe" a mancha surge a partir do deslocamento de um objeto sobre uma mancha previamente constituída, como por exemplo a tentativa de limpar a mancha de sangue, surgindo com isso um anel seco, denominado de esqueletização. (MONTEIRO, 2013, p. IIo)

Figura 4: Padrão Wipe: efeito de esqueletização

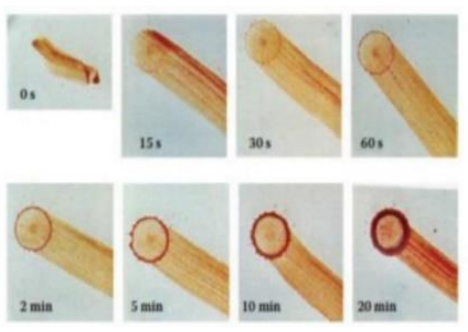

Fonte: MACIEL, 20I4.

\subsection{Padrão de impacto}

Neste quesito encontra-se configurado o padrão "Cast-off" as manchas são formadas por meio do lançamento do sangue, que estava presente em um objeto em movimento, como por exemplo a vítima ou arma do crime, sofrendo a ação de duas forças, a saber, força centrifuga e inércia. Tendo padrões lineares, as manchas permitem a identificação da quantidades de golpes aplicados e a direção da sua execução. Aqui também é possível identificar os padrões de baixa, média e alta velocidade, no padrão de baixa velocidade a 
mesma é relativa a gravidade normal que gera manchas com diâmetro igual ou superior a $4 \mathrm{~mm}$, com isso não é geradas fragmentações das gotas, a exemplo do derrame de sangue, no padrões de média velocidade o diâmetro das manchas ficam entre i a $4 \mathrm{~mm}$, tendo uma aplicação maior de quantidade de energia. Nos padrões de alta velocidade as manchas possuem Imm de diâmetro, e ocorrem em crimes que envolvem disparos. (MONTEIRO, 2013, p.113-117)

Figura 5: Representação esquemática do mecanismo de geração do padrão de manchas cast-off produzidas pela movimentação de um objeto contundente.

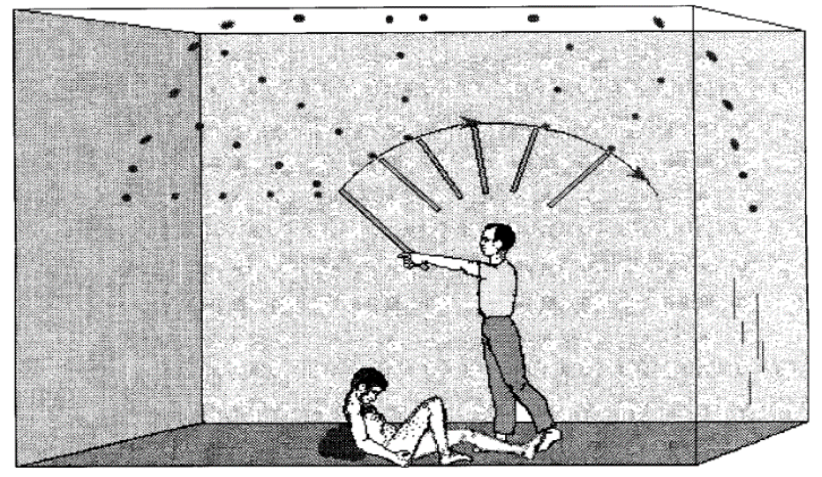

Fonte: GUAZZELLI, 2018

\subsection{Padrões heterogéneo}

Tânia Marisa Braz Nogueira a partir dos seus estudos pontua que este padrão é obtido por meio dos vazios e sombras e se caracteriza:

Pela ausência de sangue numa determinada mancha ou padrão de manchas de sangue que supostamente seria contínuo Pode resultar da presença de objetos ou pessoas naquele local no momento do evento e que posteriormente foram movidos ou retirados, facto este que poderá fornecer indicações extremamente valiosas ao investigador, nomeadamente acerca do tipo de objeto que foi movimentado através da análise dos contornos do vazio observado. (James \& Kish, 2005 apud NOGUEIRA, 2013, p.69)

Por sua vez, Inês Viana de Paula Monteiro coloca que padrão de mancha de sangue heterogéneo é marcado pela ausência de mancha, o fator gerador desse acontecimento é a mudança de direção do objeto durante o derrame do sangue. Neste padrão também é classificado o anéis de bolha que são estruturas circulares verificadas ao redor da mancha de sangue, após a sua secagem. (MONTEIRO, 2013, p. II8) 


\section{CASO PRÁTICO}

No dia 8 de setembro de 2019 na cidade de Alumínio (SP) Aline Dantas, i9 anos, foi vítima de violência sexual seguido por homicídio praticado por Heronildo Martins Vasconcelos, 45 anos, a vítima saiu para comprar fraldas para filha e não retornou mais, o acusado seguiu Aline e aproveitou a pouca movimentação da rua para levá-la a força para uma mata na região. A delegada que acompanhou o caso, Luciane Bachir, aponta que o mesmo desde do início das investigações era o principal suspeito, sendo que esse havia praticado uma tentativa de estupro em 2012, o corpo foi localizado por meio da ajuda de cães farejadores, o desfecho da resolução do crime ocorreu definitivamente quando a perícia local detectou manchas de sangue nas folhas de árvore da mata e as mesmas apontaram a identificação da vítima, o acusado negou o crime, contudo o mesmo foi apontado como autor do crime mediante o DNA colhido no corpo de Aline, ocorreu o cruzamento genético e o laudo apontou para autoria deste, sendo indiciado por homicídio qualificado e ocultação de cadáver. (GI, 2019)

Figura 6: Caso Aline

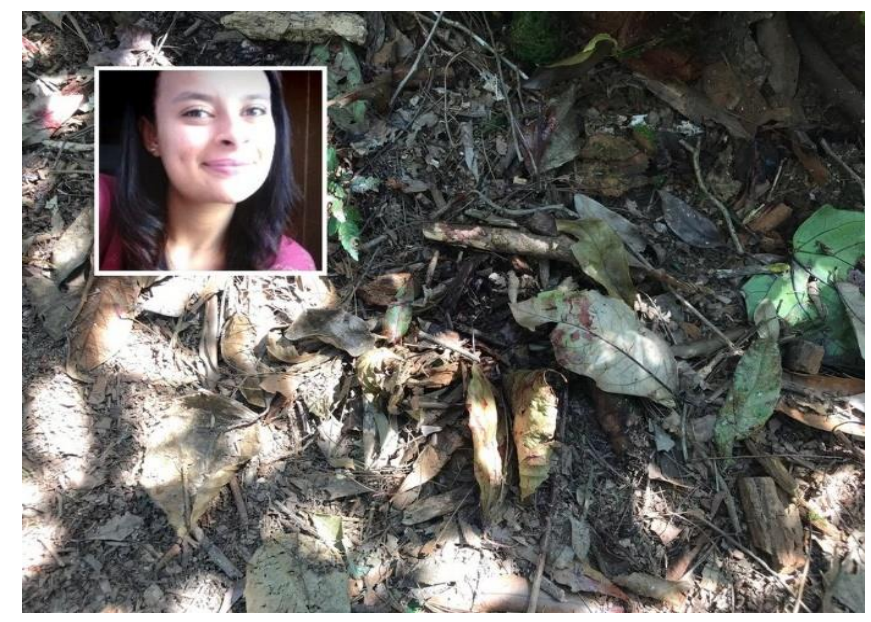

Fonte: GI, 2019

No caso em foco os peritos envolvidos desenvolveram táticas padrões seguidas nesta área, primeiramente estes ao chegarem na área da mata realizaram uma avaliação inicial do local antes mesmo de iniciar a busca por vestígios, após esse momento essencial, os mesmos localizaram e recolherem os vestígios depositados nas folhas de árvore, com isso foi 
descartado outros vestígios sem fins criminalista. A recolha foi realizada usando os equipamentos adequados tendo em vista que os vestígios estavam depositados ao lar livre expostos as condições climáticas, correndo risco de sofrer degradações, sucedeu os testes de presunção e espécie para confirmação que se tratava de sangue humano, superado esta fase, as amostras foram transportadas para o laboratório para conferir a compatibilidade do sangue encontrado com os dados genéticos da vítima e do autor.

Por sua vez, o registro fotográfico ganha grande relevância neste contexto, o mesmo tem respaldo no Código de Processo Penal, em seu artigo i64, o perito após analisar a cena do crime deve registrar de diferentes ângulos a mesma, auxiliando na elucidação das investigações, para além disso, as fotografias irão refletir na discrição escrita dos laudos periciais, uma vez que esta expõe aspectos complexos do local analisado. Nesse contexto investigativo, o laudo pericial, se apresenta como um documento importante dentro de um processo judicial, tendo em vista que o magistrado apoia-se nesse meio técnico cientifico para proferir uma decisão imparcial e justa, com isso o laudo caracteriza-se como uma prova capaz de apontar aspectos crucias do delito, como autoria, dinâmica dos fatos e sua materialidade, o perito responsável pela elaboração do mesmo, deve descrever suas impressões captadas, além de recorrer as perspectivas das testemunhas, a fim de formar uma peça escrita fundamentada concluindo os eventos ocorridos no local do crime. (MONTEIRO, 2010, p. 25)

Em suma o perito ao chegar na cena do crime tem duas opções dependendo do objetivo da pesquisa, quando é solicitado ao mesmo apenas uma interpretação das origens dos padrões das manchas de sangue, ocorre imediatamente ainda no local, sendo indicado as características das manchas de sangue e os padrões por elas constituídas, contudo se for requisitado uma reconstrução do crime, o mesmo procederá com a discrição dos tipos de padrões de manchas de sangue, o local de impacto de forma a suceder a formulação de um esquema dos eventos ocorridos.

\section{CONSIDERAÇÕES FINAIS}

Com isso, por meio do exposto infere-se que o sangue é um vestígio biológico muito frequente no contexto criminal, e devido as suas propriedades físicas, aspectos biológicos e 
componentes acaba por se consolidar como um fluido extremamente rico em elementos, os quais são aplicados e usados no meio forense. Verificou-se também que a análise dos distintos padrões das manchas de sangue aliados com autopsia médico-legal proporciona a possibilidade de reconstrução das cenas do crime, dessa forma esse fator cria condições para que seja colhido aspectos primordiais sobre o delito sucedendo na sua possível resolução. Diante disso, quando o perito encontra uma mancha de sangue e realiza sua análise tornase possível tanto a identificação da origem do sangue, como também o ato violento que causou a sua expulsão do corpo, e logo em seguida pode ser descartadas versões que não condizem com os fatos averiguados.

Vale pontuar que a dinâmica produzida pelos peritos dentro do âmbito criminal norteia as decisões judiciais, tendo em vista que as provas documentadas fundadas em parâmetros científicos corroboram com a formulação das sentenças nos tribunais, assim o perito envolvido com a análise dos padrões de manchas agem de forma cautelosa e objetiva, tendo ciência que um erro pode dificultar na solução de todo o enredo ocorrido no crime. A relevância destes profissionais nestes casos é respaldada, pois suas ações colaboram para dar celeridade ao desenvolvimento do processo por meio provas apresentadas, beneficiando as partes envolvidas.

Mediante aos fatos apresentados depreende-se que as manchas de sangue depositadas na cena do crime conduz ao perito produzir robustos indícios criminais, no contexto brasileiro onde existe a morosidade no âmbito judicial e os crimes violentos, como homicídio, que tem taxas alarmantes de crescimento, a utilização de tais vestígios como fonte de investigação resultando na identificação de suspeitos, toma proporções notórias, estabelecendo a verdade, e contribuindo para a devida aplicação da justiça interferindo na redução da impunidade satisfazendo os anseios sociais em prol de uma segurança pública de qualidade. Por isso, a utilização destas análises técnicas precisam ser fortalecidas no âmbito pericial, cabe ao Poder Judiciário, incrementar medidas que amplie os recursos destinados a área de investigação de vestígios hemáticos, a fim de obter equipamentos tecnológicos avançados contribuindo para obtenção de resultados mais preciso, sucedendo também a sistematização e padronização desta área. 


\section{REFERÊNCIAS}

BEVEL, T., \& GARDNER, R. M. (2002). Bloodstain Pattern Analysis, with an Introduction to Crime Scene Reconstruction. Florida: CRC Press. Apud NOGUEIRA, Tânia Marisa Braz. Análise de Padrões de Manchas de Sangue - A importância médico legal. Disponível em:

<https://webcache.googleusercontent.com/search?q=cache:iANb5IUGITgJ:https://core.a c.uk/download/pdf/302909II2.pdf $+\& c d=1 \& h l=p t-B R \& c t=c l n k \& g l=b r>$. Acesso em: 28 de julho de 2021.

CANelas NetO, Antonio Augusto. Perfis de Manchas de Sangue: do local de crime à

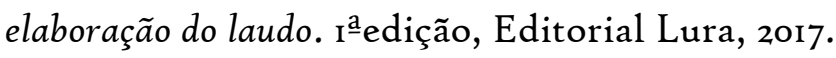

Caso Aline: polícia confirma que manchas de sangue em folhas de árvores são da vítima. Gr, São Paulo, 4 de outubro de 2019. Disponível em: <https://gi.globo.com/sp/sorocabajundiai/noticia/2019/ro/o4/caso-aline-policia-confirma-que-manchas-de-sangue-emfolhas-de-arvores-sao-da-vitima.ghtml>. Acesso em: 28 de julho de 2021.CROCE, Delton; CROCE JÚNIOR, Delton. Manual de medicina legal. 6. ed. rev. São Paulo: Saraiva, 2009

DURKHEIM, Émile. As regras do método sociológico. i3.ed. São Paulo: Nacional, i987.

FREIRE, Jose Jozefran Berto. Da doutrina e do método em medicina legal. Ensaio epistemológico sobre uma ciência biopsicossocial. São Paulo: USP - Digital Library, 2009.

GUAZZELLI, Lia Nara de Moraes. Análise pericial de manchas de sangue para elucidação da dinâmica de crimes violentos. Disponível: <https://ipog.edu.br/wpcontent/uploads/2020/II/lia-nara-de-moraes-guazzelli-4II6I713.pdf $>$. Acesso em: 3 I de julho de 202I.

JAMES, S. H., \& KISH, P. E. (2005). Principles of Bloodstain Pattern Analysis: Theory and Practice. USA: Taylor \& Francis Group. Apud NOGUEIRA, Tânia Marisa Braz. Análise 
de Padrões de Manchas de Sangue - A importância médico legal. Disponível em: <https://webcache.googleusercontent.com/search?q=cache:iANb5IUGITgJ:https://core.a

c.uk/download/pdf/302909112.pdf $+\& c d=1 \& h l=p t-B R \& c t=c l n k \& g l=b r>$. Acesso em: 26 de julho de 202I.

MACIEL, Denise Rabelo. Análise do Padrão de manchas de sangue em local de crime: revisão de literatura. Disponível em: 〈http://www.bibliotecadigital.unicamp.br/document/?code $=00094318 \mathrm{r} \&$ opt $=4>$. Acesso em: 3i de julho de 202I.

MONTEIRO, Inês Viana de Paula. Vestígios Hemáticos no local de crime sua importância Médico-Legal. Disponível em: 〈https://repositorioaberto.up.pt/bitstream/10216/26904/2/Vestgios\%20Hemticos\%20no\%2olocal\%20de\%20cri me\%20\%20Sua\%2oImportncia\%2oMdico\%2oLegal.pdf $>$. Acesso em: 29 de julho de 2021.

NOGUEIRA, Tânia Marisa Braz. Análise de Padrões de Manchas de Sangue - A importância médico legal. Disponível em: <https://webcache.googleusercontent.com/search?q=cache:iANb5IUGITgJ:https://core.a c.uk/download/pdf/302909112.pdf $+\& \mathrm{~cd}=\mathrm{r} \& \mathrm{hl}=\mathrm{pt}-\mathrm{BR} \& \mathrm{ct}=\mathrm{clnk} \& \mathrm{gl}=\mathrm{br}>$. Acesso em: $30 \mathrm{de}$ julho de 2021. 